\title{
The estimation trend of Malaysian SME occupational safety and health statistic
}

\section{Abstract:}

The statistic on occupational safety and health has received considerable attention in the SME industry regarding to the vital role of the SME in the Malaysian economy to become a developed country by the year 2020. However, the official statistic specific on SME related occupational safety and health still unavailable. Thus, the secondary data related to estimation statistic refer to the Department of Statistic (DOS) since 2001 until 2012 were used. Estimation related statistic is adapted from the Global Estimates of Occupational Accidents and Work-related IIInesses 2014. The total number of occupational accident and fatalities average high within ten years. Whereas a number of the accident decrease during 2002 to 2007 with the involvement of 85926 to 56339 cases, nevertheless, four years later trend drastically increased. Approximately ten thousand fatal occupational related diseases as 2014. In addition, the cost of compensation claims related occupational accident report increase in 2012 as well as disease and survival recipient. Overall cost of occupational accident increase every year. Presently, this study provided useful hints of implication of ignoring safety to encourage improvement of Occupational Safety and Health (OSH), enhance effectiveness of company operational cost, and stimulate prevention at the SME level substantially great approach to the Malaysian economic development.

Key Words: Accident Cost, Estimation Accident Statistic, Occupational Accident, Occupational Disease, Occupational Health and Safety, SME.

\section{Introduction}

Recently, integration occupational safety and health with the organization's operations highly practical, since it more than reducing the number of accidents but can also increase the firm's productivity and economic and financial results (2). However, researchers have paid less attention on the demand of statistical evidence, which reflected obstruct improvement occupational health and safety management in SME industry (3). Statistical data provide essential knowledge on the level of occupational accidents and work-related diseases in the SMEs industry; person involves, characteristic and time, place, frequency, cause and effect, where and how they occur. Hence, statistical data facilitates decision-making related to prevention and $\mathrm{OSH}$ promotion (1). The Malaysian occupational safety and health has increased considerably in recent ten years, in spite of the legal reforms launching Occupational Safety and Health Act (OSHA) in 1994. Critically, the statistic data from DOS revealed occupational accident in Malaysia are in alarming situation. Over the past decade, Malaysia experience has been dramatically increased in number of commuting accidents from 2008 in the year 2012 was
Nor Azma binti Rahlin ${ }^{*}$, Munawar Mustafa ${ }^{\#}$, Abdul Halim Abdul Majid ${ }^{*}$, Nor Azma binti Rahlin ${ }^{\star}$

*Faculty of Business Management and Accountancy, University Sultan Zainal Abidin (UniSZA), 21300 Kuala Terengganu, Malaysia.

(a)thman Yeop Abdullah Graduate School of Business (OYAGSB), University Utara Malaysia (UUM), 06010 Sintok, Kedah Malaysia. \#School of Business, University Utara Malaysia, 06010 Sintok, Kedah, Malaysia.
Corresponding Author: Nor Azma binti Rahlin Email: emazmarina@gmail.com (c) 2016 IJOSH All rights reserved.

about 19041, 20810, 22036, 24804 and 25616, respectively. In other hand, fatalities number shows an increasing trend from 2001 to 2012, start at beginning 2001 with the lowest 958 cases and rise to higher at the pick 1254 cases in 2011. Apart from that, number of Malaysian occupational accident also higher compares to Asia country, cost of occupational accident substantially high (4). This large number of accidents have a significant effect on the human cost (5), such as commuting, fatalities, and validity, and survival recipient was resulting significantly high in the amount of compensation claims $(6,7)$.

The issue of occupational safety and health statistic has received considerable attention in the SME industry regarding to the vital role of the SME in the Malaysian economy to become a developed country by the year 2020. The SME industry increasingly important in the most countries in the global including Malaysia, SMEs also has been recognized as a back bone of Malaysia economic development (8). The role of SME in the nation can be illustrated through their vast contribution in the economic activity, and considered as a stepping stone of the economic growth in both developed and developing countries all 
around the world (9). Currently, SMEs is the biggest contributor to the number of business establishment, which is comprised of $97.3 \%$ to the total business establishment (10). Thus a large number of SMEs establishment provided $59 \%$ employment for rural and urban growing labor force. The SMEs characteristic reveals the power as medium of dynamic and flexible tool in the economic growth (11). Consequence to the higher number of established and contribution, SME also notable contribute a higher number of occupational accident compares to the large company (12-14). Roughly, SME recorded 80 (4) to 90 percent of the total occupational accident according to SOCSO (15).

However, the official statistics related occupational safety and health specific on the SME are unavailable (16) due to incapability of SME lead to the underestimation cost of occupational accident and disease. Additionally, rising statistic evidence from SMEs has unfortunately been difficult regarding to a high level of under- reporting (17) statistic in this sector $(18,19)$, Department of Statistics (DOS) Malaysia is not analysing data by the firm size so it is challenging to make a conclusive statement of the SMEs accident and cost. Several authors miss reported the statistic of occupational safety and health due to the lack of the statistic specifically on SME industry (13,14,20-22). In otherdand, some authors establish their own method to estimate the occupational statistic (23), however its not standardize statistic at global level. There is an urgent need to address the safety problems in the SME industry through statistic approach to demonstrate cost of ignoring safety at the workplace is higher than cost of ensuring safety.

This atmosphere drives several negative effects to the work environment involving high cost of workmen's compensation insurance, high medical cost and high cost of administration, property damage, insurance premium, suffering, and tarnished image of the organization, owner and negative effect to the employees (24). Generally, statistic record shows the occupational accident and diseases level in Malaysia still far beyond the target, especially in the most risky industry like SME (4). In addition, official statistic related occupational accident and disease is most useful proof to demonstrate the real situation in the SME industry (25). This study would be able to portray an alternative action toward increasing safety and health also stimulate the SME industry growth.

Thus, it is a good opportunity for the current article, to take up the challenge to show the real Malaysian SME occupational safety level via the statistical evidence. Therefore, the purpose of this study is to review related articles to provide threatened empirical evidence for it and estimate the statistic related occupational safety and health in Malaysian SME industry according to the SEARO attribution fraction (AF) based on the International Labor Organization (ILO) guideline formulation method to increase accuracy of the statistical data estimation. Moreover, significant information from statistical estimation would be valuable for policy makers and the community by showing the size of the problem (26), in improving efficiency and thereby enhancing the effectiveness (27), plan for rapid organizational growth and innovation (28), financial and nonfinancial performance (5) and interestingly country economic competitiveness will eventually improve (29). Besides that, the estimation study has offered several advantages for the SME owner as well as researchers in order to reduce the accident rate, and hence the personal injuries and material damage, and simultaneously improves working conditions, which raises employees' motivation and reduces their absenteeism, construct a positive influence on the firm's image, reputation, productivity and innovation as well as boost the financial performance of the company $(5,30)$. The estimation of the SME industry path the way of occupational safety and health programs and be supported development of Malaysia.

\section{International research estimation of occupational safety and health}

There is specific research on a principle obligatory calculation of occupational safety and health is estimating occupational accident and disease phenomena at the global. Essential estimation of the UK since (31) has been continuing with many authors from various countries. A series of global estimation research by (32) and fellow researchers team $(1,31,34-40)$ contribute advancement of knowledge in the calculation of estimation occupational related accident and disease. Summarized of literature review of the most related articles on estimation tabulated according to the title, country, year of publication, source of data and author as presented in table $\mathrm{I}$.

Table I: Summary of Studies on Global Estimates of Occupational Accident and Occupational-Related Disease

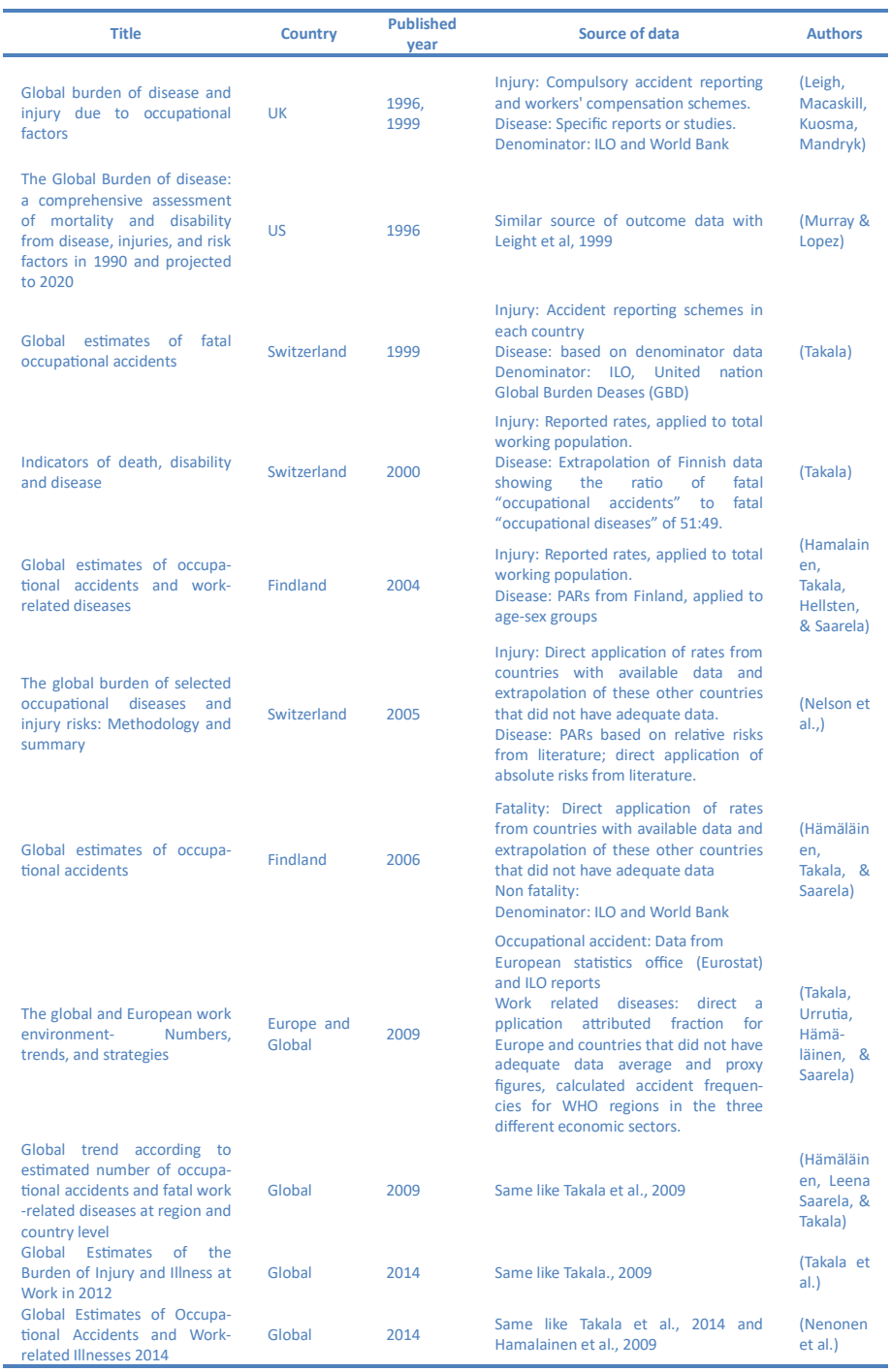


Generally, global estimation at 1999 of (33) estimated that 1.1 million work-related deaths occur every year. Next, in the year 2005 related finding identified that around 100,000,000 occupational injuries and 700,000 occupational diseases happen annually (38). Latest results of 2006 and 2007 estimated that approximately 312,000 per annum the amount of occupational disease occur. Then, researchers collaborate under ILO project in one committee with the aim provided latest estimations and update estimation both of the global number of occupational accident and data disease based year 2010 and 2011 respectively.

Over the decade, estimation of global occupational safety and health facing slightly innovation however upon new definition enforcement by the ILO required new estimation associate with the changes. For example, new definition of work day absence involving a change number of days from three to four days is relevance for global re estimation 2014. An increasing number of work days in the definition contribute consequence effect to another component of occupational related accident for instance number of injuries and fatalities. Besides that, updated statistical data at country level would be able to provide better information regarding to occupational and related disease. Thus, affordable approaches from several researchers is consistent with the demand of reliable and accurate data for international estimation in the ILO.

Table II: Representative countries by region

\begin{tabular}{|c|c|}
\hline Region & \multicolumn{1}{c|}{ Representative countries } \\
\hline High & Australia, Canada, France, Italy, Norway, Singapore, Switzerland \\
\hline AFRO & Zimbabwe, Algeria, Ghana, Togo, Tunisia \\
\hline AMRO & Argentina, Dominican Republic, Belize, Costa Rica, Mexico \\
\hline EMRO & Broatia, Czech Republic, Estonia, Latvia, Lithuania, Poland, Romania, Turkey, Ukraine \\
\hline EURO & Kyrgyzstan, Korea republic, Macau, China, Malaysia, Myanmar, Philippines, Thailand \\
\hline SEARO, WPRO & B \\
\hline
\end{tabular}

Source: Global Estimates of Occupational Accidents and Work-related Illnesses 2014

Note: HIGH: high income countries, AFRO: Low- and middle- income countries of the African Region, AMRO: Low- and middle- income countries of the Americas, EMRO: Low- and middle- income countries of the Eastern Mediterranean Region, EURO: Low- and middle- income countries of the European Region,
SEARO: Low- and middle- income countries of the South East Asia Region, WPRO: Low- and middle- income countries of the Western Pacific Region

Moreover, the Asian country ILO is one of six regional groups of countries receive crucial attention from ILO in the occupational safety and health estimation. Malaysia has been categorized under SEARO as presented in table II. Particularly, a special calculation regarding to availability data of the representative country on fatality rate and AF was corrected. Whereas, the earlier work of (41) on AF standard doesn't match to the low income countries, taking into consideration revisable AF of high income country. Then, implementation of AF divided by two; original AF; high income country and revise AF; low income country. Besides that, neuropsychiatric AF has been revised regarding two different work hazard conditions and chemical exposure orientation as much as technology advanced (42). However, for the purpose of this article, attentMoreover, the Asian country ILO is one of six regional groups of countries receive crucial attention from ILO in the occupational safety and health estimation. Malaysia has been categorized under SEARO as presented in table 2. Particularly, a special calculation regarding to availability data of the representative country on fatality rate and AF was corrected. Whereas, the earlier work of (41) on AF standard doesn't match to the low income countries, taking into consideration revisable AF of high income country. Then, implementation of AF divided by two; original AF; high income country and revise AF; low income country. Besides that, neuropsychiatric AF has been revised regarding two different work hazard conditions and chemical exposure orientation as much as technology advanced (42). However, for the purpose of this article, attention will be given much more on SEARO adjusted AF (41) where is Malaysia belong to, then formula adjusted to match on the calculation with available data related Malaysian SME.

\section{Source of Data}

In this article, all term related estimation occupational is defined as (43). The source of the data obtained from the trusted resources such as department of statistic and social security organization that have similar or comparable conditions. Secondary data was hired both of the bodies to ensure high accuracy basis for calculations of the estimated number in Malaysian SME occupational accident and disease, corresponding employment figures of related data of accidents occurred since the year 2001 until the year 2012 are obtained.

Detailed accident statistics for instance, the number of employed in the active economic population and a number of workers by work categories; working proprietors, active business partners and unpaid family workers, full-time paid employees: managerial, professional and executive, technical and supervisory, clerical and related occupations, general workers and part-time paid be acquired from official report of DOS and SOCSO.

Employment figures have been obtained from the Labor Force Statistics, Malaysia (44-46). When either employment or fatality rate was not available for the year in question, data on the employment in the current year available were estimated as adjusted formula.

\section{Methods}

The present study is the first to systematically identify articles safety related study in Malaysia. The goal is not to establish a comprehensive list of the publications about estimation occupational safety and health in Malaysia, nevertheless to understand safety research aspects in Malaysian SME. OSHA in Malaysia still in the phase of introducing of standard setting start from 2004 until 2010 and currently within 2011 to 2015 we are in the phase towards an enforcement level safety and health (47) (Department of Occupational Safety and Health, 2009) consider new as clearly mentioning in the Occupational Safety Health Master Plan 15 (OSH MP 15).

Reflection of this atmosphere, there are only a small number of safety research had been done in Malaysia. A several number of studies had been done in the safety domain from a various 
research interest under sub domain occupational safety and health, safety management, occupational safety management, safety management practices and etc. (15,48-51). However, there is insufficient literature of OSHA in SME, there is no research had been done in the estimation related occupational safety and health in the SME industry especially in Malaysia, then the review has been wider at the global level due to this issue.

Next, comprehensive scientific literature was searched through several databases, Emerald, Springle, ProQuest, Inspec, PubMed, Science Direct and Web of Science to provide criteria and bases for the estimation of related occupational accident estimation suitable for use in the SME work environment. The literature review critically discovers previous research of estimation occupational accident, occupational burden of diseases and injuries, reported accidents, surveys of occupational illnesses and injuries, attributable fractions, economic cost estimates for work related injuries and ill-health. Besides that, recently published papers in literature review the calculation method of statistical data aspect from different countries at the global level.

This statistical estimation of occupational safety and health analysed using Microsoft Excel due to the aim of this study. Where does Microsoft excel is much more convenient for data entry secondary data, easy-to-use for many basic data analysis for instance descriptive data analysis (52). Study divided into two parts; (a) estimation number occupational related accident involving Number of SME occupational accident according to SME sizes, Trend of the SME Report Accident According To Gender; 2001 Until 2012, Trend Total SME reported accident according to categories of workers, and Trend of total SME related occupational accident and (b) estimation work more on fatal occupational-related diseases including the number of fatal occupational related diseases in 2001 to 2012 and the number of deaths attributed to hazardous substances according to gender. This estimation towards fatal occupational related disease was compensated by the population of adjusted attributable fractions (AF) based on original work of (41) in The Global Burden of Disease (GBD) so called fatal work related disease commonly known as "occupational diseases" in legal term. The detail of descriptive estimation of Malaysian SME occupational accident and related disease formulated as follows.

\section{Occupational related accident}

In the part one estimation mainly as a global method varies with the available data from SOCSO and DOS and procedure backup with possible related information from several government sources. Assumption SME occupational accident and related disease is 80 percent (17) of total occupational accident according to Director of SOCSO (15). Four detail formula for occupational related accident explain as follows.

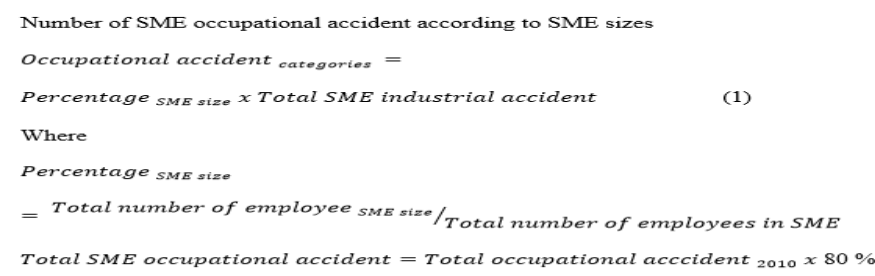

Estimation based on available data on the number of employees in SME size for the year 2010

(Data available from Summary report economic census 2010, Department of Statistic, Malaysia)

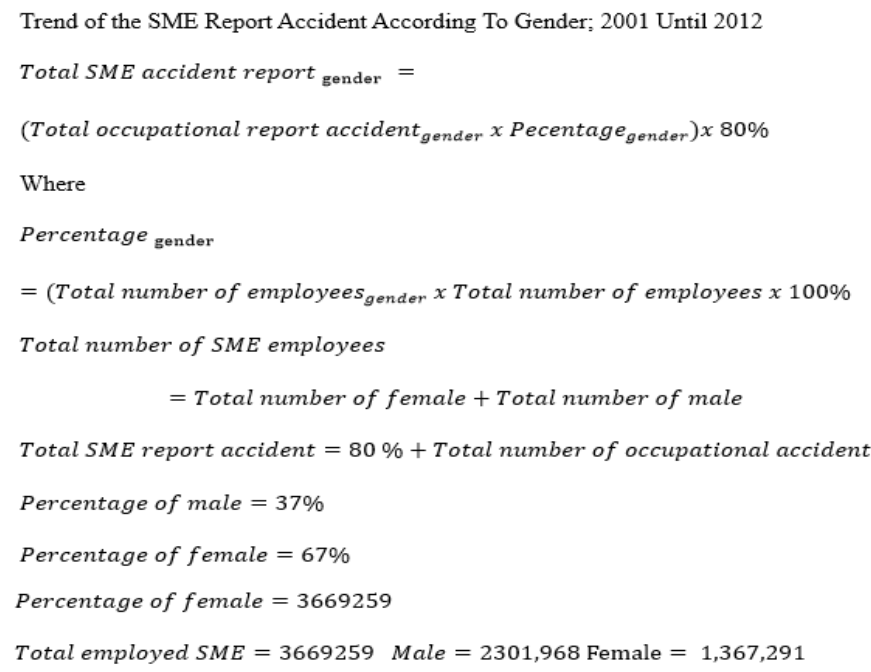

Estimation percentage of female and male employees in the employment are based on available data in economic census for the year 2010 (53). Number of reported accident per year based on data SOCSO data (7).

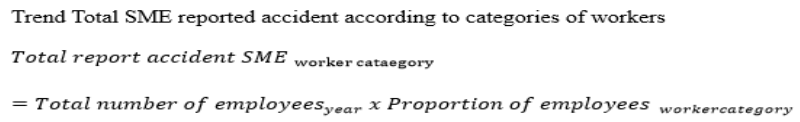

\section{Estimation occupational related disease}

Revise AF were used to obtain the next following estimation related work disease the number of fatal occupational related diseases and estimated number of deaths attributed to hazardous substances according to gender ratio analysed based on revised AF. Specific revised AF also applied on neuropsychiatric. Outcome of this study would be improve the accuracy of the statistical data in Malaysian SME industry. 


\section{Estimation of fatal occupational related disease}

To obtain estimates of fatal occupational related diseases according at the Malaysia level, the proportion of employment SEARO regional estimates number of Global Estimates of Occupational Accidents and Work-related Illnesses 2014 were used (1). SEARO is adjusted AF implement by ILO for Asia region. While the total number of employment yearly is based on employed number in the principal labour force statistic, Malaysia time series 1980-2013 (45).

Number of fatal occupational related diseases in 2001 until 2012 Number of fatality disease $e_{\text {ear }}$

$$
=\text { Portion type of dissease } x \text { Number of SME employment }
$$

Where

Number of SME employment $t_{\text {year }}=$ Number of employment $x 80 \%$

Portion type of disease $=S E A R O_{\text {portion on disease }}$

Portion type of disease $=$

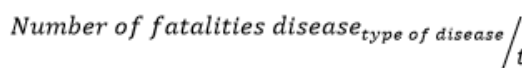
total number of fatalities disease

Number of employment are based on number employed in the principle labour force statistics, Malaysia, 1982-2013 from Malaysia, Department

SEARO proportion disease data based on information in Global Estimates of Occupational Accidents and Work-related IIInesses 2014 (1)

SME Estimated number of deaths attributed to hazardous substances according to gender

SME total deat $h_{2014}=\left(\frac{\text { Total number of employment }}{100000} \times 21.5\right) \times 0.8$
Where
Total employment $=13440900$
Total death $=2889.7935$
SME Total death $h_{2014}=2311.8348$
Number of death $h_{\text {type of cancer }}=$ Percentage $e_{\text {type of cancer }} \times$ SME number of death
Percentage $e_{\text {type of cancer }}=$ number of death $h_{\text {type of cancer }} \times$ Total number of death

Considered the fatality rate per 100000 workers is 21.5 in Asia and Island now categories under SEARO region $(1,34)$. Number of employment based on employed number in the Principal Statistics of Labour Force, Malaysia, February 2014 (45). Data on estimation percentage $e_{\text {type }}$ cancer and estimated percentage attribute to hazardous substance according to gender based on Global Estimates of Occupational Accidents and Work-related Illnesses 2014.

\section{Result and Discussion}

In the figure I, the number of occupational accident is presented by SME size. The highest number of occupational accident owned by small size with the number 14756 follows by micro size about 13000 cases and the lowest occupational accident among three SMEs size are medium size with only 8484 cases. It shows that medium size record almost 50 percent lower than the small size, while the number of occupational accident record in small size and micro size record not much different.

Figure 1 Number of SME occupational accident based on SME sizes

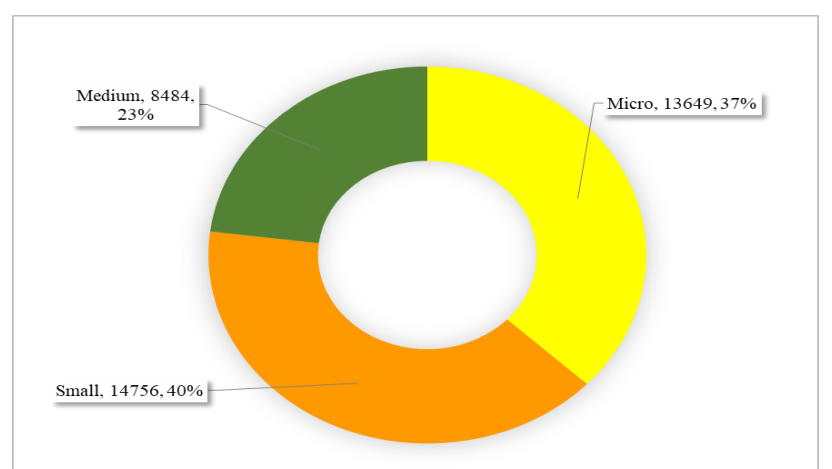

Next following discussion will focus on regenerating explicit Malaysia SME finding based on general Malaysia occupational accident in order to overcome the identified loop hole. Where previous methodology of the estimates of non-fatal occupational accidents calculated statistic is underestimated $(23,40,54)$. Old-school number of figures for instance, number of occupational accidents in such SEARO countries including Malaysia relatively ultimate good working conditions of infant stage safety and health $(1,26,33,34,38,40)$. Table and figure illustrated ten year trend of Malaysian SME occupational accident and disease statistic effected of decreasing in economic activities during 2008. Actual facts show that dependent of work activities on economic in during a world recession cause the lowest number of fatal and non-fatal occupational related accident and disease (40). However, down turn trend of occupational related accident and disease number never significant to the growth of recipient numbers and the cost compensation claims in Malaysia. Background of the SME such as categories worker, gender in the population drive tabulated frequency of report accident in Malaysian SME.

Table III shows total SME report accident based on categories of workers. Ten year trend for working properties, active business partners and paid family workers, full time paid employees and part time paid employees disease, record high at the beginning 2001 and low at 2012 parallel with employment growth. Part time employees lowest in 2007 around 1989 cases compared to 2001, number of occupational accident about 3000 which is two times lower than full time paid employees in the same year.

Table III Total SME Reported Accident Based on Categories of Workers

\begin{tabular}{|c|c|c|c|c|c|c|c|c|c|}
\hline & 2004 & 2005 & 2006 & 2007 & 2008 & 2009 & 2010 & 2011 & 2012 \\
\hline $\begin{array}{c}\text { Working proprietors, active business } \\
\text { partners and unpaid family workers }\end{array}$ & 12947 & 11458 & 10923 & 10551 & 10298 & 10469 & 10795 & 11218 & 11347 \\
\hline Full-time paid employees & 53744 & 47564 & 45340 & 43799 & 42749 & 43459 & 44810 & 46565 & 47104 \\
\hline Managerial, professional and executive & 7194 & 6367 & 6069 & 5863 & 5722 & 5817 & 5998 & 6233 & 6305 \\
\hline Technical and supervisory & 7194 & 6367 & 6069 & 5863 & 5722 & 5817 & 5998 & 6233 & 6305 \\
\hline Clerical and related occupations & 12879 & 11398 & 10865 & 10496 & 10244 & 10415 & 10738 & 11159 & 11288 \\
\hline General workers & 26970 & 23869 & 22753 & 21979 & 21452 & 21809 & 22487 & 23368 & 23638 \\
\hline Part-time paid employees & 2440 & 2160 & 2059 & 1989 & 1941 & 1973 & 2035 & 2114 & 2139 \\
\hline
\end{tabular}


The higher number of occupational accident full time paid employees influence of the real number of this work categories in the SME population itself. Furthermore the number of occupational accident in Full-time paid employee's category is far greater than working proprietors, active business partners and unpaid family worker categories with ratio 3:1. Indeed, clerical and general worker comprises of 70 percent from full time employee's reasons of high number occupational from both of this work categories. General worker categories are direct expose with the work hazard, and chemical may courses high risk of having injuries and illness. Moreover, demographically, general worker constitutes 50 percent of SME employees, low income family, low education and lack of competency (10).

Figure 2 present ten years' time series number of SME report accident according to gender since 2001 until 2012. From the figure, it clearly shows that total occupational accident in a declining trend since the beginning 2001 (68741) until 2008 (43990), however trend change to upward after 2008. Moving forward to 2012, number of total SME occupational accident increase every year pick at 48472 in 2012. Female are more than half of SME population where is the SME population has 67 percent of female employees compare only 33 percent of male employees. The evidence indicates that SME employees are lacking skill and competency, realistic solution to improve levels of safety in SME via special training (4).

Figure 2 Total SME Accident Report According To Gender; 2001 Until 2012

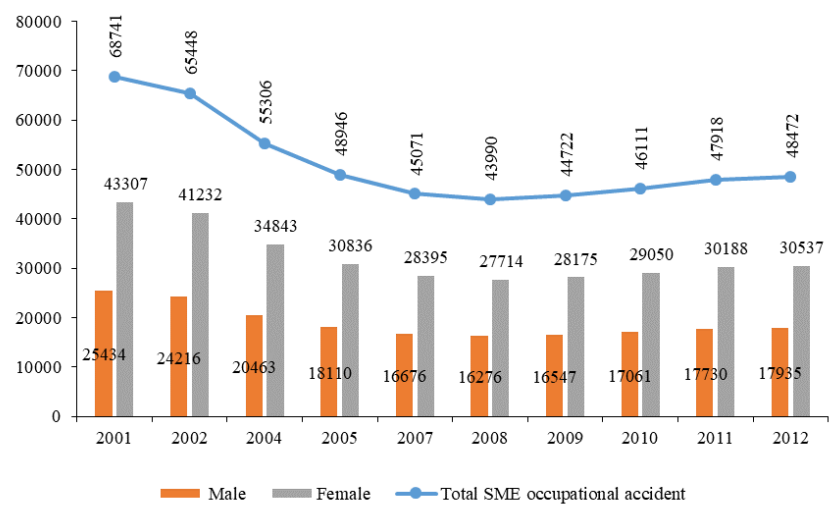

Time series of statistic related occupational accident; commuting, industrial fatalities and total accident report illustrated in the figure 3. Nice appearance a couple of the bar chart is industrial or occupational accident and total accident report per one hundred thousand employees decreased in the first eight years from 2001 ( 0.77 and 6.87) to 2008 (2.88 and 4.40), however the next following three years; 2009 and 2010 and 2011 the number of occupational continuously increase. Contrast, the number of commuting accidents is gradually increasing within ten years. On the other hand, fatalities per one thousand employees are likely commuting accident starting low at 0.77 per one thousand employees, then increase almost 0.2 per thousand every year to reach 1.00 per thousand employees at the end of 2011.
Figure 3 Total SME Report Accident Occupational Accident

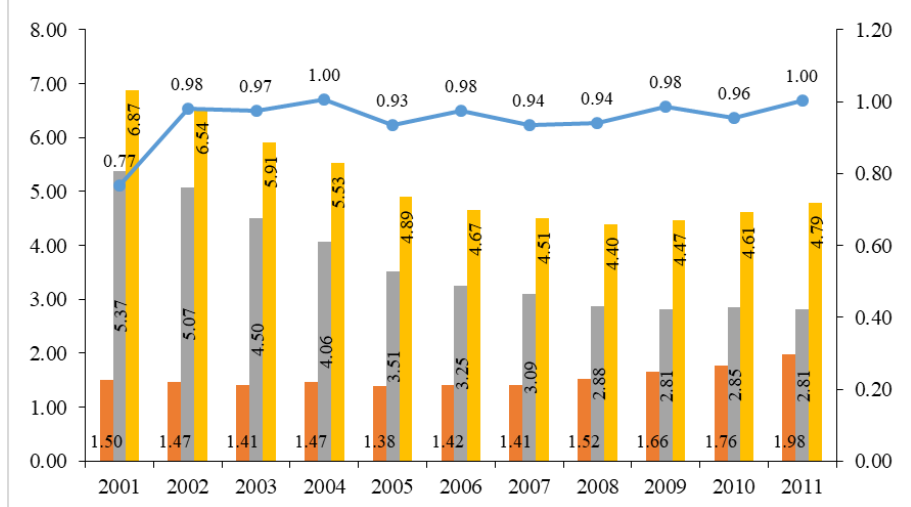

cummuting accident $\quad$ industrial accident $\quad$ Total accident report $\rightarrow$ fatalities

Note: fatalities/ 1000 employees and commuting, Industrial and total accident /10000 Estimation based on $80 \%$ of the total number reported occupational accident provided by SOCSO

Even though, the number of occupational statistic not stable and the trend is changeable from decreasing to increasing trend, nevertheless the most importance evidence from number of SME recipient related occupational accident and disease show both two types of recipient are substantially rising from 2002 until 2012 as figure 4. Number of disease recipient stable around the average 25000 employees per year. Both of two types of recipient are disease and survival recipients are parallel, continuously increase during ten years where is survival recipient involvement are five times higher than disease recipients. Number of survival recipient is lower at 85244 in the year 2003, progressively increase during ten years to reach to 152804 employees. This increment trend of the recipient was the significant impact on the total cost of compensation claim.

Figure 4 Number of SME Recipient

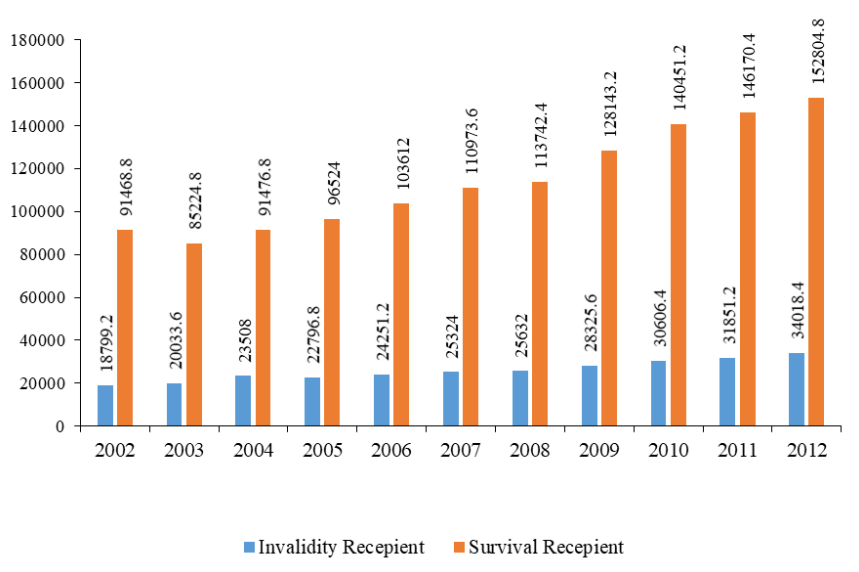

Furthermore, figure 5 present implications of occupational accident and disease such as industrial accidents, commuting in term of the financial cost. Consequently, some of the burden from compensation claim; occupational temporary, dependent, permanent, and disease cost including number of recipients; survival and disease in 2002 until 2012. This statistic data quite difference with previous data, where is all type compensation claims are in increasing trend during ten years. In 2002, cost of temporary disablement, permanent disablement, dependent and 
disease are RM 50, RM 134, RM 82 and RM 276 million, respectively. Generally, the permanent disablement cost is two times higher than temporary disablement cost, but the cost of disease is much more expensive than permanent disablement cost. Besides that, disease cost rise almost RM 50 million yearly and dramatically increase in 2010 and 2012 to RM 742 million and RM 894 million.

\section{Figure 5 Cost of SME Occupational Accident}

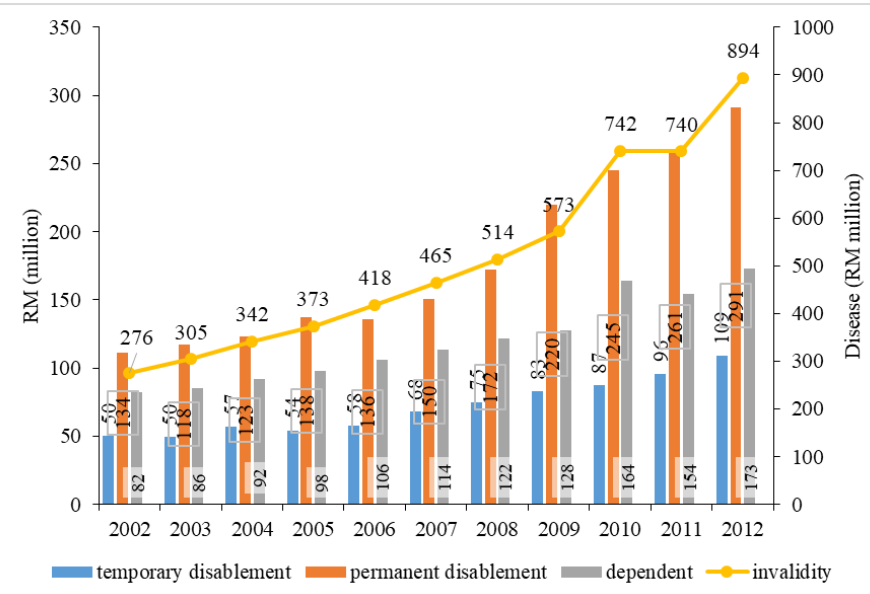

Note: Estimation based on $80 \%$ of the total number reported occupational accident provided by SOCSO

Nowadays, the latest number of fatal occupational related disease as 2014, there were still approximately ten thousand occurring in the Malaysian, SME as tabulated in table IV. The leading groups of work-related diseases in global level are circulatory diseases follows by malignant neoplasms, and both communicable diseases and respiratory diseases are closely similar. Table $V$ shows the number of deaths attributed to hazardous substance according to gender ratio. The highest frequency of death were chronic obstructive pulmonary and mesothelioma in the AF tabulation table, 973 and 617, respectively. The number of deaths between male and female value in the table 4 is estimated based on adjusted AF. It can be seen in 2014 the estimated number of disease deaths related occupational accident is 2312 . The estimates of death occupational related diseases likely bias estimation between gender either underestimate for women or overestimates for men in Asian countries in the especially in the Malaysia (26).

Table IV The Number of Fatal Occupational Related Diseases In 2001 To 2012

\begin{tabular}{|c|c|c|c|c|c|c|c|c|c|}
\hline & & 2005 & 2006 & 2007 & 2008 & 2009 & 2010 & 2011 & 2012 \\
\hline & & 8036 & 8220 & 8430 & 8528 & 8718 & 9520 & 9828 & $\begin{array}{c}1017 \\
9\end{array}$ \\
\hline $\begin{array}{l}\text { communicable } \\
\text { disease }\end{array}$ & 0.17 & 1394 & 1425 & 1462 & 1479 & 1512 & 1651 & 1704 & 1765 \\
\hline $\begin{array}{l}\text { Malignant } \\
\text { neoplasms }\end{array}$ & 0.19 & 1541 & 1577 & 1617 & 1636 & 1672 & 1826 & 1885 & 1952 \\
\hline $\begin{array}{l}\text { Neuropsychiatric- } \\
\text { conditions }^{2}\end{array}$ & 0.01 & 106 & 108 & 111 & 112 & 115 & 125 & 129 & 134 \\
\hline $\begin{array}{l}\text { Circulatory } \\
\text { diseases }\end{array}$ & 0.45 & 3638 & 3722 & 3817 & 3861 & 3947 & 4310 & 4449 & 4608 \\
\hline $\begin{array}{l}\text { Respiratory } \\
\text { diseases }\end{array}$ & 0.14 & 1112 & 1137 & 1166 & 1180 & 1206 & 1317 & 1360 & 1408 \\
\hline Digestive diseases & 0.02 & 133 & 136 & 140 & 142 & 145 & 158 & 163 & 169 \\
\hline $\begin{array}{l}\text { Genitourinary } \\
\text { system }\end{array}$ & 0.01 & 112 & 115 & 118 & 119 & 122 & 133 & 137 & 142 \\
\hline
\end{tabular}

Table V Estimated Number of Deaths Attributed To Hazardous Substances According To Gender Ratio

\begin{tabular}{|c|c|c|c|c|c|}
\hline \multirow[t]{2}{*}{ Cancer } & \multicolumn{2}{|c|}{$\begin{array}{l}\text { Estimated percentage } \\
\text { attributed to hazardous } \\
\text { substance }\end{array}$} & \multicolumn{2}{|c|}{$\begin{array}{l}\text { Number of death to } \\
\text { hazardous substance }\end{array}$} & \multirow[t]{2}{*}{$\begin{array}{l}\text { no. of } \\
\text { death }\end{array}$} \\
\hline & male & female & male & female & \\
\hline Mouth and oropharynx & 1 & 0.5 & 5 & 2 & 7 \\
\hline Esophagus & 3.3 & 1.1 & 21 & 7 & 28 \\
\hline Stomach & 3 & 0.3 & 34 & 3 & 37 \\
\hline Colorectal & 1 & 0.5 & 10 & 4 & 14 \\
\hline Liver & 0.2 & 0.1 & 2 & 1 & 3 \\
\hline Lung & 0.02 & 0.01 & 0 & 0 & 0 \\
\hline Mesothelioma & 21.1 & 5.3 & 513 & 104 & 617 \\
\hline Skin & 10 & 2 & 12 & 2 & 15 \\
\hline Breast & - & 4.6 & - & 61 & 61 \\
\hline Cervix Uteri & - & 0.7 & - & 5 & 5 \\
\hline Ovary & - & 0.5 & - & 2 & 2 \\
\hline Prostate & 1 & - & 8 & - & 8 \\
\hline Bladder & 7.1 & 1.9 & 21 & 5 & 26 \\
\hline Leukemia & 0.9 & 0.5 & 3 & 2 & 4 \\
\hline Other and unspecified & 6.8 & 1.2 & 96 & 17 & 112 \\
\hline Neuropsychiatric & 1 & 1 & 2 & 2 & 3 \\
\hline Cardiovascular & 1 & 1 & 98 & 98 & 196 \\
\hline $\begin{array}{l}\text { Chronic obstructive } \\
\text { pulmonary }\end{array}$ & 18 & 6 & 730 & 243 & 973 \\
\hline Asthma & 21 & 13 & 100 & 61 & 161 \\
\hline Other respiratory disease & 1 & 1 & 7 & 7 & 13 \\
\hline \multirow[t]{2}{*}{ Genitourinary diseases } & 1 & 1 & 13 & 13 & 26 \\
\hline & & & & & 2312 \\
\hline
\end{tabular}

Note: Revised attribute fraction from Global Estimates of Occupational Accidents and Work-related Illnesses 2014

\section{Conclusion}

From the literature review $\mathrm{OSH}$ atmosphere in Malaysia at alarming situation, 80 percent of total occupational accidents and related disease contribute by the SME industry. Whereas occupational related disease estimated according SEARO adjusted $\mathrm{AF}$ and 21.5 fatality rate. More than that, the results from the overall estimation indicated that RM1467 million in 2012 resulting from annual increment of compensation claims required special attention on 50 percent female employees who are working as a full time general worker in the small size SME. While both of Circulatory and Chronic obstructive pulmonary recognized as main killer disease in the SME industry. In conclusion, the reality of safety efforts strongly depend on the statistical data on reducing the number of occupational accident and related disease promoting better $\mathrm{OSH}$ in the Malaysian SME industry.

\section{References}

1. Nenonen N, Saarela KL, Takala J, Kheng LG, Yong E, Ling LS, et al. 2014 Global Estimates of Occupational Accidents and Work-related Illnesses Temperer; 2014.

2. O'Toole M. The relationship between employees' perceptions of safety and organizational culture.2002. J Safety Res. (2):231-43.

3. Santos-Reyes J, Beard AN. Assessing safety management systems. 2002. J Loss Prev Process Ind. 15(2):77-95.

4. Thye LL. Improving OSH in the SMI: A Malaysia Experience. Kuala Lumpur: NIOSH Malaysia; 2010.

5. Fernández-Muñiz B, Montes-Peón JM, Vázquez-Ordás CJ. Relation between occupational safety management and firm performance. 2009. Saf Sci. 47(7):980-91.

6. Johari B. 2013. OSH MS implementation: toward improving safety. Kuala Lumpur;. p. 1-58. Available from: www.dosh.gov.my 
7. Mohammed Azman AM. 2013. Return on prevention: occupational safety and health promotion. Accident Prevention Seminar 2013. Kuala Lumpur: Social Secutrity Organization. p. $x x-x x$.

8. MITI. 2011. International trade and industry report 2010. Petaling Jaya.

9. Boocock G, Shariff MNM. 2005. Measuring effectiveness of credit guarantee schemes: Evidence from Malaysia. Int small Bus Manag J. 23:427-54.

10. Department of Statistic Malaysia. Economic census 2011: profile of SMEs [Internet]. Kuala Lumpur; 2011. Available from: http://www.smecorp.gov.my/ vn2/sites/default/files/07 SMEAR_11-12 ENG Economic Census 2011_0.pdf

11. National SME Development Council. 2012. Summary. SME Master Plan 2012 -2020: catalysing growth and income. 1st ed. Kuala Lumpur: National SME Development Council. p. 1-61.

12. A. Floyde, G. Lawson, S. Shalloe, R. Eastgate MD, Floyde A, Lawson G, Shalloe S, Eastgate R, D'Cruz M. 2013. The design and implementation of knowledge management systems and e-learning for improved occupational health and safety in small to medium sized enterprises. Safety Science. 6976.

13. Cagno E, Micheli GJL, Masi D, Jacinto C. 2013. Economic evaluation of OSH and its way to SMEs: A constructive review. Saf Sci. 53:134-52.

14. Ma Q, Yuan J. 2009. Exploratory study on safety climate in Chinese manufacturing enterprises. Saf Sci. 47(7):1043-6.

15. Surienty L, Hong KT, Hung DKM. 2011. Occupational safety and health in SMEs in Malaysia prelimilinary investigation. J Glob Enterprenuesh. 1(1):6575.

16. Cunningham TR, Sinclair R, Schulte $P$. Better understanding the small business construct to advance research on delivering workplace health and safety. 2015. Small Enterp Res [Internet]. Routledge; 2015

17. Targoutzidis A, Koukoulaki T, Schmitz-Felten E, Kuhl K, Oude Hengel KM, Rijken E, et al. 2014. The business case for safety and health at work: costbenefit analyses of interventions in small and medium-sized enterprises. Bilbao: European Agendy for Safety and Health at Work; 2014. xxx-xxx p.

18. Department of Labour. 2006. Regulatory impact statement for proposed workplace safety ACC levy discount for small businesses in six high risk industries: The nature and magnitude of the problem and the need for government action. Available from: http://www.osh.govt.nz/publications/research/acclevy0603/pg1.html.

19. Adams M, Burton J, Butcher F, Graham S, McLeod A, Rajan R, et al. 2002. Aftermath: The social and economic consequences of workplace injury and illness. Wellington.

20. Brooks B. 2008. The natural selection of organizational and safety culture within a small to medium sized enterprise (SME). J Safety Res 39(1):73-85.

21. Kines P, Andersen D, Andersen LP, Nielsen K, Pedersen L. 2014. Improving safety in small enterprises through an integrated safety management intervention. J Safety Res. 44:87-95.

22. Kongtip P, Yoosook W, Chantanakul S. 2008. Occupational health and safety management in small and medium-sized enterprises: An overview of the situation in Thailand. Saf Sci. 46(9):1356-68.

23. Legg S, Battisti M, Harris L-A, Laird I, Lamm F, Massey C, et al. 2009. Occupational health and safety in small businesses. Welllington.

24. Silva K, Ishiwatari Y, Takahara S. 2014. Cost per severe accident as an index for severe accident consequence assessment and its applications. Reliab Eng Syst Saf.123:110-22.

25. Fernandes M. 2009. Statistics for Business and Economics. The American Statistician. 342-343 p.

26. Driscoll T, Takala J, Steenland K, Corvalan C, Fingerhut M. 2005. Review of estimates of the global burden of injury and illness due to occupational exposures. Am J Ind Med.;48:491-502.

27. Smallman C, John G. 2001. British directors perspectives on the impact of health and safety on corporate performance. 38:227-39.

28. Veltri A, Pagell M, Johnston D, Tompa E, Robson L, Amick III BC, et al. 2013 Understanding safety in the context of business operations: An exploratory study using case studies. Saf Sci. 55:119-34.

29. Lahiri S, Levenstein C, Nelson DI, Rosenberg BJ. 2005. The cost effectiveness of occupational health interventions: prevention of silicosis. Am J Ind Med. 48(6):503-14.

30. Johnson SE. 2007. The predictive validity of safety climate. J Safety Res. 38 (5):511-21.

31. Leigh J, Macaskill P, Kuosma E, Mandryk J. 1999. Global burden of disease and injury due to occupational factors. Epidemiology. 10:626-31.
32. Takala J, Hämäläinen P, Saarela KL, Yun LY, Manickam K, Jin TW, et al. Global Estimates of the Burden of Injury and Illness at Work in 2012. J Occup Environ Hyg. 11(5):326-37.

33. Takala J. Global estimates of fatal occupational accidents. Epidemiology. 1999:10:640-6.

34. Hämäläinen P, Takala J, Saarela KL. 2006. Global estimates of occupational accidents. Saf Sci. 44:137-56.

35. Murray CJL, Lopez A. 1996. A comprehensive assessment of mortality and disability from disease, injures and risk factors in 1990 and projected to 2020 . The Global Burden of Disease.1-51.

36. Takala J. 2000. Indicators of death, disability and disease. AsianPacific Newsl Occup Heal Saf. 1(7):4-8.

37. Hamalainen P, Takala J, Hellsten A, Saarela K. 2004. Global estimates of occupational accidents and work- related diseases. Tamperer.

38. Nelson DI, Concha-Barrientos M, Driscoll T, Steenland K, Fingerhut M, Punnett $\mathrm{L}$, et al. 2005. The global burden of selected occupational diseases and injury risks: Methodology and summary. Am J Ind Med. 48(6):400-18.

39. Hämäläinen P, Leena Saarela K, Takala J. 2009. Global trend according to estimated number of occupational accidents and fatal work-related diseases at region and country level. J Safety Res. 125-39.

40. Takala J, Urrutia M, Hämäläinen P, Saarela KL. 2009. The global and European work environment- Numbers, trends, and strategies. Scand J Work Environ Heal Suppl. 15-23.

41. Nurminen M, Karjalainen A. 2001. Epidemiologic estimate of the proportion of fatalities related to occupational factors in Finland. Scand J Work Environ Heal. 27:161-213.

42. Masi D, Cagno E. 2015. Barriers to OHS interventions in Small and Mediumsized Enterprises. Saf Sci 71:226-41.

43. Denisov Él, Mazitova NN, Shemetova M V, Chelishcheva MI, Chesalin P V. 2011. ILO plan of action (2010-2016) on occupational safety and health and new list of occupational diseases. Med Tr Prom Ekol. (3):7-13.

44. Department of Statistic Malaysia. 2014. Selected Demographic Statistic Estimation Malaysia 2014. Kuala Lumpur.

45. Department of Statistic Malaysia. 2014. Labour Force Statistics, Malaysia, February 2014. Kuala Lumpur.

46. Department of Statistic Malaysia. 2011. Taburan_Penduduk_dan_Ciriciri_Asas_Demografi.pdf. Kuala Lumpur.

47. Deparment of Occupational Safety and Health. 2009. Occupational safety and health master plan 2015 (OSH-MP 15). Kuala Lumpur: Department of Occupational Safety and Health.

48. Hassan A, Nor Azimah CA, Chandrakantan S. 2009. Management practice in safety culture and its influence on workplace injury: An industrial study in Malaysia. Disaster Prev Manag. 18(5):470-7.

49. Mohamad Khan JK. 2003. Determinant of Occupational safety and Health Performance in Small and Medium Manufacturing Setting. Universiti Utara Malaysia.

50. Siti Fatimah B, Clarke S. 2013. Cross-validation of an employee safety climate model in Malaysia. J Safety Res. 45:1-6.

51. Wan Rosmini H. 2000. Tahap kesedaran pekerjaan berhubung dengan keselamatan dan kesihatan di tempat kerja: Suatu Kajian Kes di Hume Cemboard Berhad, Primaboard. Unpublished. Universiti Utara Malaysia.

52. Salkind NJ. 2010. Statistics for people who (think they) hate statistics: Exce 2007 edition [Internet]. 2nd ed. Thousand Oak: SAGE. Thousand Oak. 399.

53. Department of Statistic Malaysia. 2012. Economic cencus 2011: profile of small medium entreprise. Putrajaya: Department of Statistic Malaysia; 2012. 268

54. Cigularov KP, Adams S, Gittleman JL, Haile E, Chen PY. 2013. Measurement equivalence and mean comparisons of a safety climate measure across construction trades. Accid Anal Prev 51:68-77. 